\title{
Experimental techniques for the investigation of coupled phenomena in geomaterials
}

\author{
E. Romero ${ }^{\mathrm{a}}$ \\ Dep. of Geotechnical Engineering and Geosciences, Universitat Politècnica de Catalunya, 08034 \\ Barcelona, Spain
}

\begin{abstract}
The paper describes different experimental setups and techniques used to investigate coupled stress, fluid (water and air) and temperature effects on geomaterials. Two temperature controlled cells are described: a) a constant volume cell in which thermal pulses can be performed under controlled hydraulic conditions to induce pore pressure build-up during quasi-undrained heating and later dissipation; and b) an axisymmetric triaxial cell with controlled suction and temperature to perform drained heating and cooling paths under partially saturated states. The paper also presents an experimental setup to perform controlled flow-rate gas injection experiments on argillaceous rocks using a high-pressure triaxial cell. This cell is used to study gas migration phenomena and the conditions under which gas breakthrough processes occur. Selected test results are presented, which show the capabilities of the different experimental setups described to capture main behavioural features.
\end{abstract}

\section{Introduction}

The extension of geotechnical engineering applications and the research interest in multi-physics processes is becoming increasingly wider in recent years, mainly within the context of the geoenvironmental and the geosciences area. Topics such as waste confinement (at surface or at great depths using engineered barriers or host geological formations), soil pollution and remediation, assessment of seals in hydrocarbon exploration and oil field subsidence phenomena, and in the storage of $\mathrm{CO}_{2}$, are increasingly coming into prominence. These new fields of application often require the incorporation of relevant and coupled thermo-hydro-chemo-mechanical phenomena, and the introduction of new variables for a more complete understanding of the behaviour of geomaterials (soils and rocks). Reliable experimental equipment and techniques, capable of applying mechanical and geoenvironmental boundary conditions while maintaining controlled partial saturation states, together with microstructural techniques aimed at integrating information from different scales, are also required to achieve such an understanding.

The paper will focus on describing different experimental techniques used to investigate fluid (liquid and gas) and temperature effects in geomaterials subjected to controlled stress state, together with their induced couplings. In addition, selected test results will be presented to show the capabilities of the experimental setup to capture main behavioural features. The techniques have

\footnotetext{
a e-mail : enrique.romero-morales@upc.edu
} 
been developed within the context of the following studies: temperature effects on geomaterials at different saturation states [1-3], and gas migration and gas pressure breakthrough processes (creation of gas pathways) [4-5].

\section{Selected equipment and experimental techniques for coupled processes}

\subsection{Thermo-hydraulic coupling}

Thermal loads may play an important role and affect the performance of low-permeability geological formations proposed as potential radioactive waste repository. Figure 1 shows a scheme of a quasiisochoric and axi-symmetric heating cell $[3,6]$, which is used to study heating pulse tests with controlled power supply and controlled hydraulic boundary conditions. Soil dimensions are $75 \mathrm{~mm}$ in diameter and $100 \mathrm{~mm}$ high. A controlled-power heater is installed along the axis of the sample in the lower part of the cell. Different transducers are monitoring the sample response, as shown in the figure: two miniature pore water pressure transducers $\left(P w_{1}\right.$ and $P w_{2}$ in Fig. 1), three thermocouples $\left(T_{1}, T_{2}\right.$ and $\left.T_{3}\right)$, and top and lateral strain gauges attached to reduced thickness sections $(S G)$. Moreover, the cell has top and bottom valves $\left(u_{u}\right.$ and $\left.u_{b}\right)$ to apply the hydraulic conditions. The main objective is to measure the pore water pressure evolution (build-up and subsequent dissipation at constant temperature) for different temperature pulses. Throughout the course of the heating phase, the bottom drainage is usually maintained open at a constant water backpressure using an automatic pressure / volume controller, while the upper valve is kept closed. This backpressure is important since it allows measuring the pore pressure drop during the cooling phase without invading the negative range (below atmospheric conditions). The initial and external temperatures were always regulated by submerging the cell inside a temperature controlled water bath.

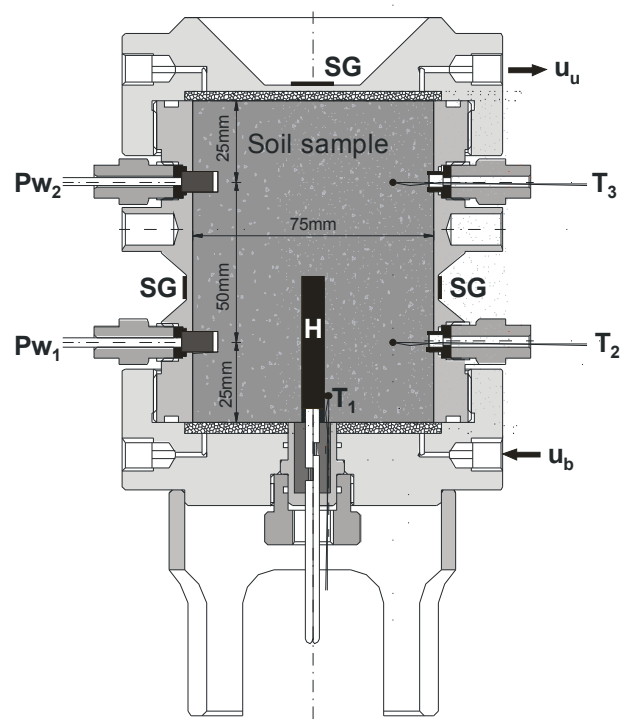

$\mathrm{H}$ - heater (length $=40 \mathrm{~mm}$ and diam. $=6 \mathrm{~mm}$ )

$\mathrm{Pw}_{1}$ - pore water pressure bottom $25 \mathrm{~mm}$

$\mathrm{Pw}_{2}$ - pore water pressure top $75 \mathrm{~mm}$

$\mathrm{T}_{1}$ - temperature heater

$\mathrm{T}_{2}$ - temperature bottom $25 \mathrm{~mm}$

$\mathrm{T}_{3}$ - temperature top $75 \mathrm{~mm}$

$S G$ - strain gauge

$u_{b}$ - water inlet

$\mathrm{u}_{\mathrm{u}}$ - water outlet

Fig. 1. Quasi-isochoric axi-symmetric heating cell $[3,6]$. 


\subsection{Thermo-hydro-mechanical coupling}

Reliable experimental equipment and techniques, capable of applying elevated temperatures while maintaining partial saturation and stress state conditions, are also required to improve the understanding of drained thermal effects and propose new thermo-hydro-mechanical constitutive frameworks. Figure 2 presents the layout of a controlled-suction axi-symmetric triaxial cell (to apply different hydraulic and stress states), specifically updated for accurate temperature control by using a forced-convection system driven by a gear pump. The hydraulic state (prescribed suction) is controlled by axis translation technique applied at both ends of the sample through high air-entry value ceramic discs. This double drainage ensures a significantly shorter equalisation stage for liquid pressure equalisation, an important advantage when testing low permeability unsaturated soils. The deformational response of the material along heating and cooling paths is carefully monitored using local instrumentation. Axial displacements are measured internally by miniature LVDT transducers directly mounted on the specimen. Radial deformations on two diametrically opposite sides and throughout the specimen height are measured by means of a movable electro-optical laser system installed outside the chamber. This system can be used as radial displacement scanners by moving the sensors throughout the sample height. This way, the whole profile of the sample from the base to the top cap can be measured and the average radial strain determined. This approach is best suited for the determination of the degree of saturation of the sample and when the specimen tends to deform non-uniformly due to end restraint effects. The triaxial equipment is described elsewhere [2].

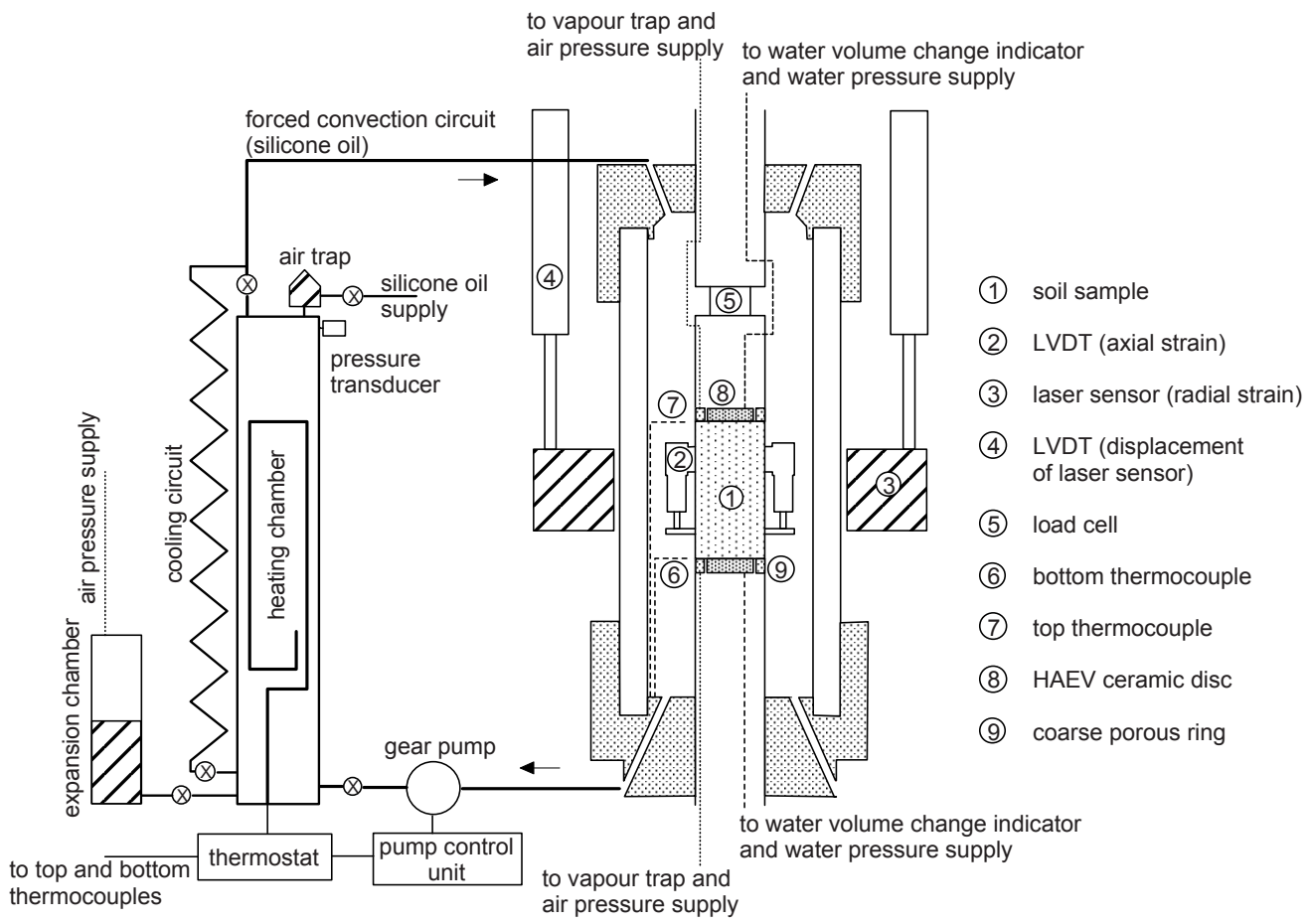

Fig. 2. Temperature and suction controlled axi-symmetric triaxial cell [2]. 


\subsection{Gas injection tests under controlled stress state}

Understanding gas transport processes is also one of the key issues in the assessment of radioactive waste repository performance. To this aim, a research programme was started to develop and calibrate an experimental setup to perform controlled flow-rate gas injection experiments using a high-pressure triaxial cell to apply isotropic/anisotropic stress states on argillaceous rock samples. The aim of the tests is to study gas migration phenomena and the conditions under which gas breakthrough processes occur, as well as to analyse the influence of the gas injection rate, the stress state, the orientation of rock discontinuities and other relevant hydro-mechanical variables (porosity, degree of saturation, ...). Figure 3 shows a scheme of the experimental setup and the high-pressure triaxial cell adapted to test samples $50 \mathrm{~mm}$ in diameter and with a minimum height of $20 \mathrm{~mm}$. This axi-symmetric equipment allows performing water permeability and air injection tests at elevated pressures (maximum confining pressure of $20 \mathrm{MPa}$ supplied by compressed air bottles). An air / oil / water interface is used to fill the cell with water as safety precaution and as thermal bath. Two neoprene membranes separated by an aluminium foil were used to confine the sample and to slow down air diffusion problems through this interface. Top and bottom caps in contact with sample were connected to the inlet and outlet lines through coarse metallic discs. The equipment uses four automatic pressure / volume controllers, two for gas (a high-pressure one connected to the injection point and a low-pressure controller at downstream point), and two for water (two low-pressure pistons for upstream and downstream points), which can be used in combination (for example, air injection and water pressure at downstream). The gas injection controller has a maximum range of $20 \mathrm{MPa}$ (volume $500 \mathrm{~mL}$ ), and is able to control volume rates between $10^{-4} \mathrm{~mL} / \mathrm{min}$ and $100 \mathrm{~mL} / \mathrm{min}$ (volume resolution $<5 \mathrm{~mm}^{3}$ and pressure resolution of $10 \mathrm{kPa}$ ). An electronic balance together with an air / water interface is specifically prepared in the downstream circuit to measure air outflow (downstream circuit initially full of water) during the air injection tests. Sample axial deformation is recorded by an external LVDT.

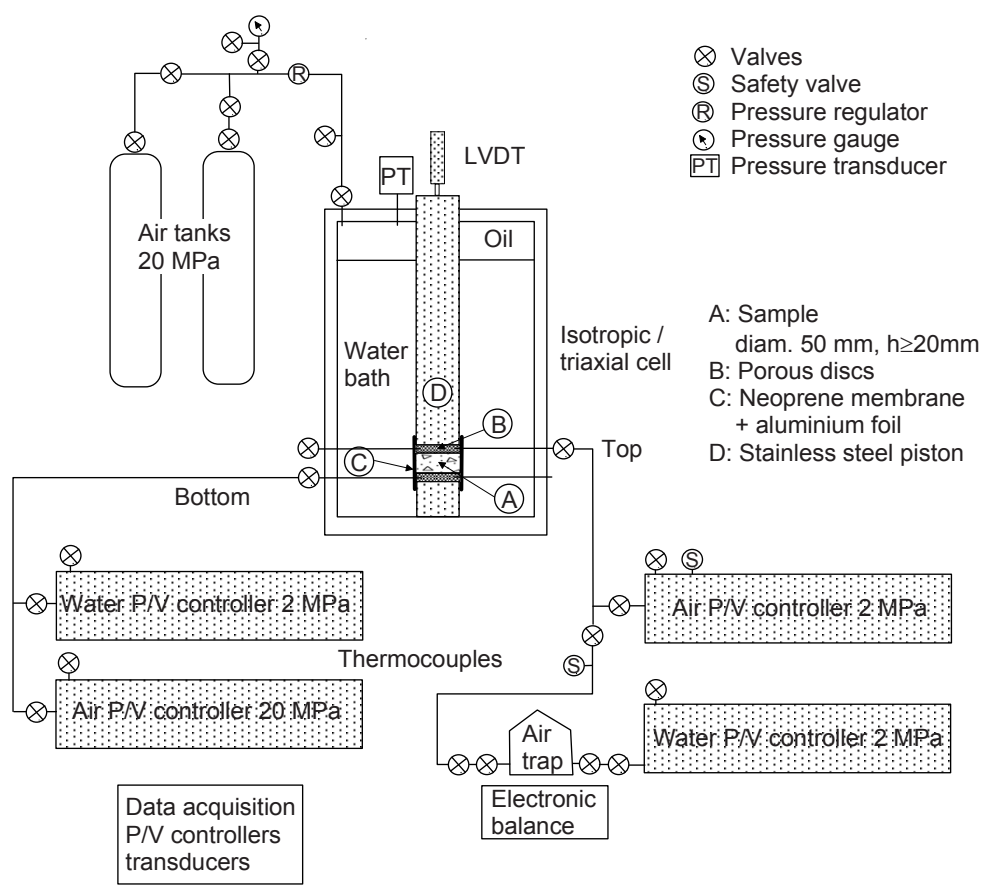

Fig. 3. Experimental setup for controlled flow-rate gas injection experiments using a high-pressure triaxial cell [5]. 


\section{Selected test results}

\subsection{Thermo-hydraulic coupling}

This section presents the results obtained along a thermal stage using the constant volume cell (Fig. 1 ), in which the heater reached a maximum temperature of $85^{\circ} \mathrm{C}$. Tests were carried out on Boom clay (Mol, Belgium), a slightly overconsolidated Tertiary clay (20\%-30\% kaolinite, $20 \%-30 \%$ illite and $10 \%-20 \%$ smectite). Figure $4 \mathrm{a}$ presents the time evolution of temperature recorded by a thermocouple placed very near the heater $\left(T_{l}\right.$ in Fig. 1), whereas Figure $4 \mathrm{~b}$ shows the time evolution of the corresponding water pressure changes $\left(P w_{1}\right.$ and $\left.P w_{2}\right)$. Maximum pressure build-up during the initial quasi-undrained heating stage was $1.83 \mathrm{MPa}$ at $P w_{2}$ and slightly lower at $P w_{1}(1.69 \mathrm{MPa})$, which is placed near the bottom draining boundary. During quasi-undrained cooling, while returning to the initial temperature, the pore water pressure dropped to $0.13 \mathrm{MPa}$ at $P w_{2}$ and to $0.17 \mathrm{MPa}$ at $P w_{1}$. As observed, quite symmetric pressure peaks were obtained in both heating and cooling stages. Maximum values of the quasi-undrained pressurisation coefficients -defined as the pore pressure increase/decrease due to a unit temperature increase/decrease- were $0.189 \mathrm{MPa} /{ }^{\circ} \mathrm{C}$ on heating and slightly lower $0.108 \mathrm{MPa} /{ }^{\circ} \mathrm{C}$ on cooling.

During heating, pore water pressure increases due to its larger thermal expansion coefficient. The magnitude of the water pressure change depends on the rate and range of temperature increase / decrease (quasi-undrained heating and temperature dependence of the water thermal expansion coefficient), on the soil compressibility (dependent on the stress state) and thermal-expansion coefficient, the water permeability and porosity (also dependent on the stress sate), the induced damage due to pore pressure increase, as well as on the hydraulic boundary condition applied. As previously indicated, a larger pressure build-up is detected at $P w_{2}$, due to the fact that the measuring point is located at a larger distance from the draining boundary. After the heating path, pore water pressures dissipate at constant temperature towards the value applied by the hydraulic boundary condition. Pore water pressure $P w_{2}$ dissipates more slowly due to its larger distance to the draining boundary.
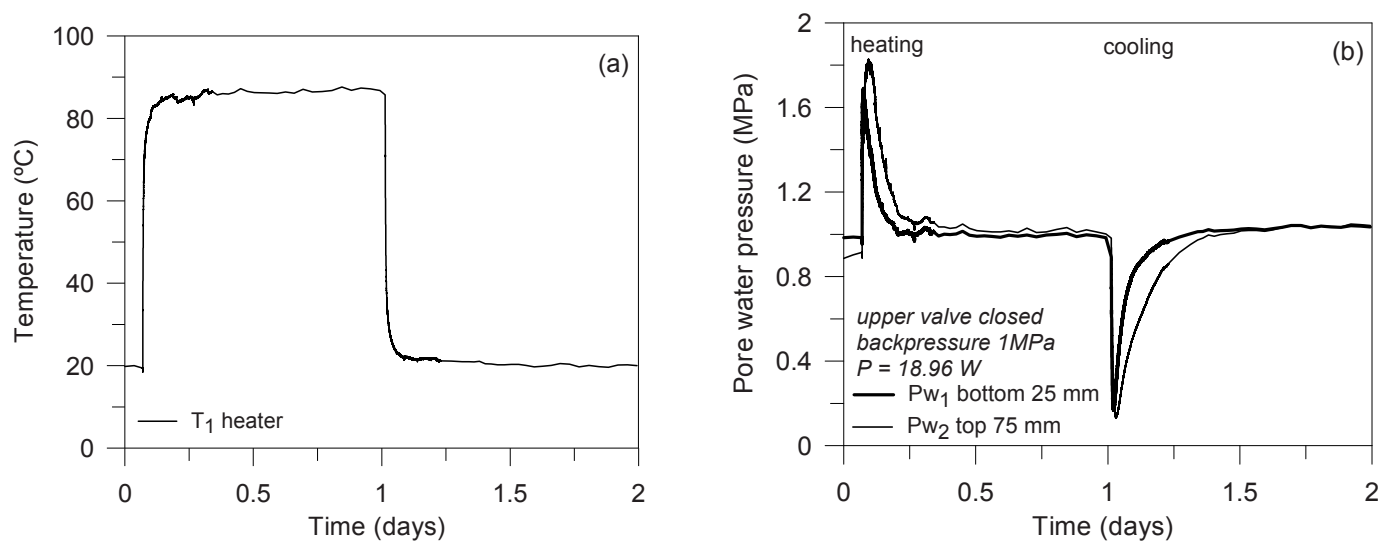

Fig. 4. Heating pulse test under constant volume. (a) Time evolution of temperature. (b) Time evolution of pore water pressures [3]. 


\subsection{Thermo-hydro-mechanical coupling}

Figure 5 shows the time evolution of volumetric strain $\left(\varepsilon_{v}=\varepsilon_{1}+2 \varepsilon_{3} ; \varepsilon_{1}\right.$ : axial strain and $\varepsilon_{3}$ : radial strain), shear strain $\left(\varepsilon_{s}=2\left(\varepsilon_{l}-2 \varepsilon_{3}\right) / 3\right)$ and water volume change, that undergoes a normally consolidated sample on a temperature change from 22 to $30^{\circ} \mathrm{C}$ under constant isotropic mean net stress $p "=1.00 \mathrm{MPa}$ and controlled matric suction $s=0.20 \mathrm{MPa}$. Tests were carried out on compacted Boom clay at an initial void ratio $e=0.68$. Compressive strains are considered positive and a negative water mass change denotes water outlet. The first phase up to $100 \mathrm{~min}$ corresponds to a quasi-undrained stage where water drainage is not allowed. Afterwards, temperature is held constant for the remainder of the pore pressure equalisation period (drained stage). This thermal consolidation phase with some water outlet is stopped after 7 days testing, corresponding to a relatively stable volumetric steady state (a volumetric strain rate of less than $0.01 \% /$ day). The isotropic rise in axial and radial strains induced under quasi-undrained conditions can be readily observed in the figure. Afterwards, a nearly isotropic thermo-plastic compression of the soil structure develops during pore pressure dissipation.

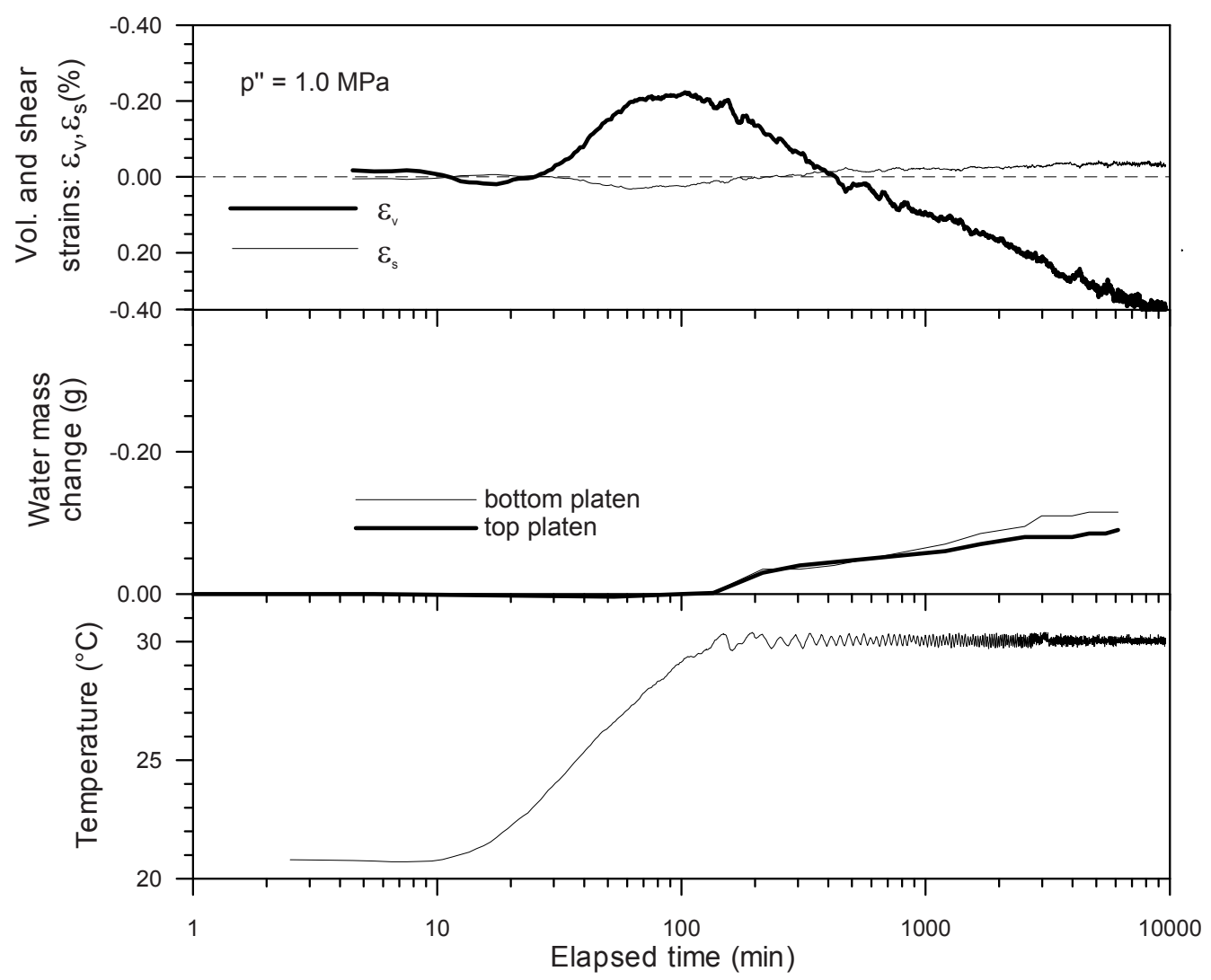

Fig. 5. Heating path under constant isotropic mean net stress and controlled hydraulic conditions. Time evolution of volumetric and shear strains, water mass change and temperature increase [2]. 


\subsection{Gas injection tests under controlled stress state}

Gas injection tests using the setup described in Figure 3 were performed on undisturbed Opalinus clay cores (dry cored and cast in resin) recovered in the shaly facies and oriented normal to the bedding (Mont Terri Underground Rock Laboratory in Northern Switzerland). After saturation, the confining pressure was increased in a ramp to $5 \mathrm{MPa}$. More than one week was let to dissipate any excess pore water pressure to atmospheric conditions. Then, top and bottom water lines were drained. Starting from an initial gas pressure of $2.0 \mathrm{MPa}$, the bottom pressure of the air injection system was increased by using controlled volume rate: $1.22 \times 10^{-2} \mathrm{~mL} / \mathrm{min}$. The top cap was maintained at $0.02 \mathrm{MPa}$. Figure 6 shows the time evolution of injection air pressure, and the outflow volume and pressure measured by the automatic air controller. Deviations from the perfect gas law for a constant mass system in the injection point, allowed estimating the injected mass of air into the sample. Figure 7 plots this time evolution of injected air mass together with the outflow air mass.

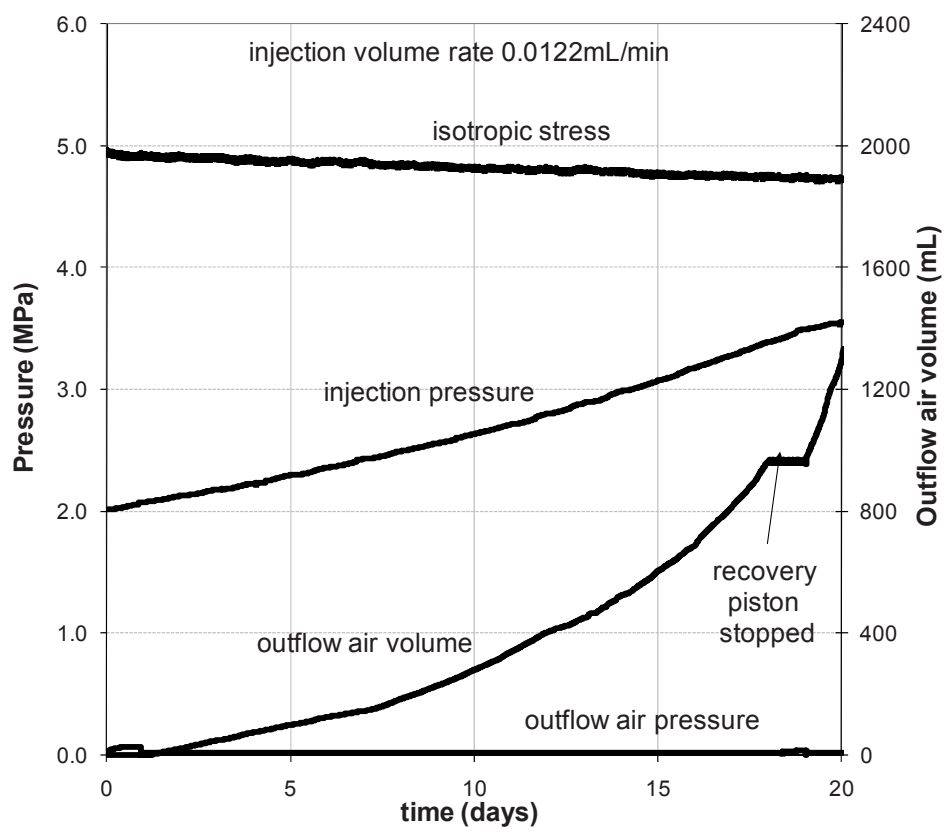

Fig. 6. Gas injection at controlled volume rate and isotropic stress conditions. Time evolution of injection pressure and outflow air pressure and volume [5]. 


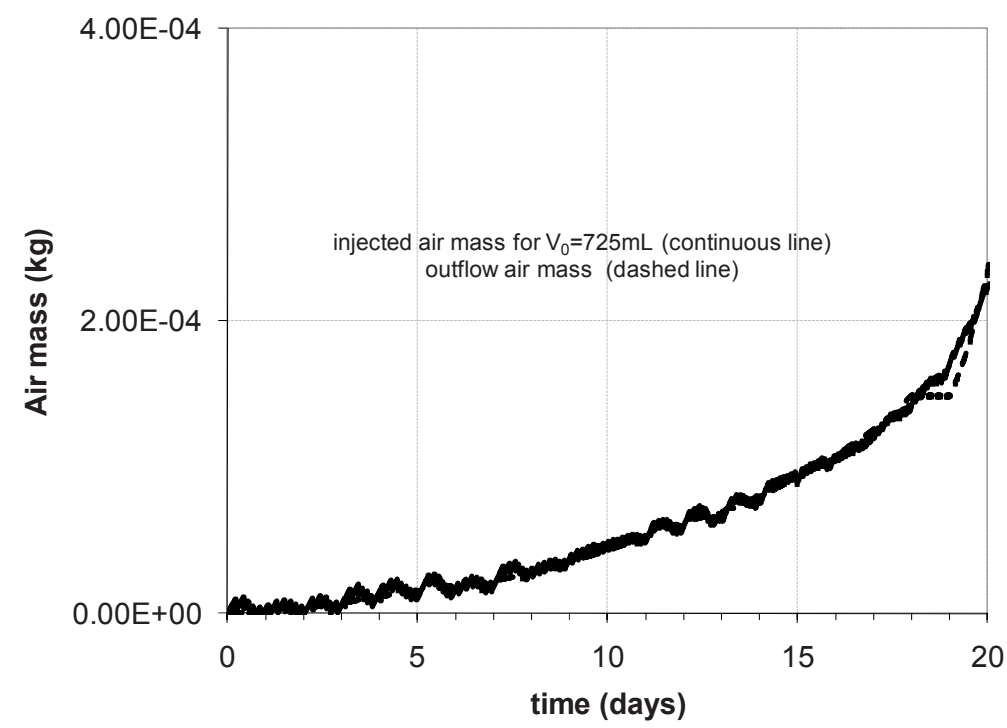

Fig. 7. Time evolution of injected air mass at controlled volume rate [5].

\section{Summary and conclusions}

Different experimental setups and cells were presented to get insight into coupled multi-physics processes in geomaterials. Selected examples were discussed to show the capabilities of these setups to capture specific behavioural features. A constant volume heating cell was presented to study pore pressure build-up and subsequent dissipation induced by heating pulses. Another temperature controlled triaxial cell, specially adapted to control partially saturated states, was also introduced. The time evolution of volume changes of a partially saturated normally consolidated sample was presented during a heating path. Sample dilation under quasi-undrained heating conditions was followed by thermo-plastic compression due to pore pressure dissipation during the drainage stage. The paper finally presented an experimental setup to perform controlled flow-rate gas injection experiments on argillaceous rocks using a high-pressure triaxial cell. Results were presented showing the capability of the experimental setup to follow the evolution of air injection pressure and mass, as well as outflow air pressure and volume.

\section{References}

1. E. Romero, A. Gens, A. Lloret, Géotechnique 53(1), 65 (2003)

2. E. Romero, Characterisation and THM behaviour of unsaturated Boom clay (PhD Thesis, UPC, Spain, 1999)

3. A. Lima, E. Romero, A. Gens, J.J. Muñoz, X.L. Li, UNSAT-WASTE 2009 (Tongji University, Shanghai, 2009)

4. D. Arnedo, E.E. Alonso, S. Olivella, E. Romero, Physics and Chemistry of the Earth 33, S237 (2008)

5. E. Romero, E.E. Alonso, P. Marshall, D. Arnedo, M. De Gracia, Fault and Top Seals - from Pore to Basin Scale (EAGE, Montpellier, 2009)

6. J.J. Muñoz, E.E. Alonso, A. Lloret, Géotechnique 59(4), 293 (2009) 